\title{
Structural Water Molecules Confined in Soft and Hard Nanocavity as Bright Color Emitters
}

Jiafeng Zhou, ${ }^{1}$ Taiqun Yang, ${ }^{1}$ Bo Peng, ${ }^{1}$ Bingqian Shan, ${ }^{1}$ Meng Ding, ${ }^{1}$ Kun

$$
\text { Zhang }{ }^{* 1,2,3}
$$

${ }^{1}$ Shanghai Key Laboratory of Green Chemistry and Chemical Processes, College of Chemistry and Molecular Engineering, East China Normal University, Shanghai 200062, China;

${ }^{2}$ Laboratoire de chimie, Ecole Normale Supérieure de Lyon, Institut de Chimie de Lyon, Université de Lyon, 46 Allée d'italie, 69364 Lyon cedex 07, France;

${ }^{3}$ Shandong Provincial Key Laboratory of Chemical Energy Storage and Novel Cell Technology, School of Chemistry and Chemical Engineering, Liaocheng University, Liaocheng, 252059, Shandong, P. R. China.

* Correspondence: kzhang@chem.ecnu.edu.cn (K.Z.) 


\section{Experimental Section}

\section{Chemicals}

All chemical reagents were directly used without any isolation or purification. 1-bromopyrene, chlorodiphenylphosphine, n-butyllithium, Tetraphenylethylene (TPE), 1-(4-Hydroxyphenyl)-1,2,2- triphenylethene (TPE-OH) were ordered from Macklin Inc., Shanghai, China. All the other organic solvents were purchased from Sinopharm Chemicals Beijing Co. Beijing, China. Ultrapure water with a resistivity of $18.2 \mathrm{M} \Omega \cdot \mathrm{cm}$ was used throughout all experiments.

\section{Synthesis}

Synthesis of Diphenyl-1-pyrenylphosphine (DPPP):

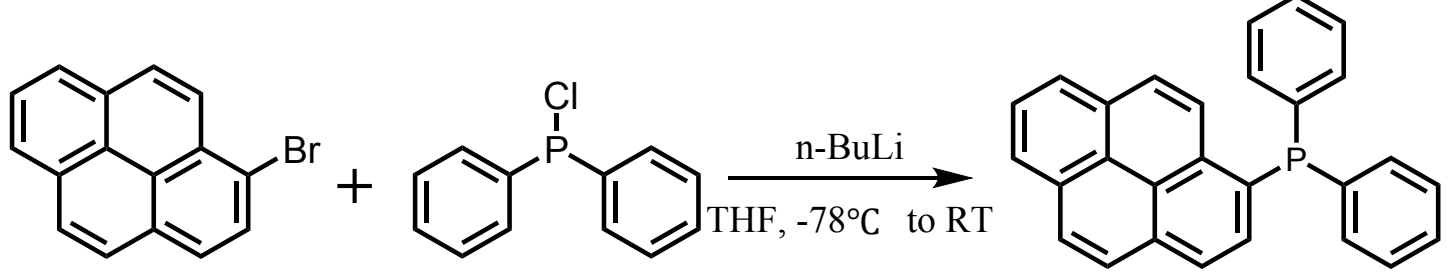

Scheme S1. Synthetic route of compound DPPP.

The synthesis of DPPP refers to literature reports. ${ }^{1}$ 1-bromopyrene ( $9.0 \mathrm{mmol}, 2.52$ g) was first dissolved in $50 \mathrm{~mL}$ THF and rapidly cooled to $-78{ }^{\circ} \mathrm{C}$. Then $\mathrm{n}$-butyllithium in hexane $(3.0 \mathrm{~mL}, 6.0 \mathrm{mmol})$ was added using a syringe and stirred for $1 \mathrm{~h}$. Next, chlorodiphenylphosphane $(7.5 \mathrm{mmol}, 1.65 \mathrm{~g})$ was added to the organolithium solution, and the mixed solution was allowed to warm up to room temperature. After $18 \mathrm{~h}, 20 \mathrm{~mL}$ water was added slowly, and THF was removed by reduced pressure evaporation. The resulting aqueous phase was extracted with $30 \mathrm{~mL}$ dichloromethane for three times. Then the combined organic phase was washed with $20 \mathrm{~mL}$ water for two times. The organic phase was then dried over anhydrous sodium sulfate and filtered, and the solvent was removed by reduced pressure evaporation. DPPP was obtained as a white solid with a yield of $49 \%$.

${ }^{1} \mathrm{H}-\mathrm{NMR}(400 \mathrm{MHz}$, DMSO-d6) $\delta$ (ppm): 8.65 (dd, J = 9.2, $4.8 \mathrm{~Hz}, 1 \mathrm{H}), 8.35$ (dd, J = 14.7, 7.4 Hz, 2H), 8.29-8.21 (m, 3H), 8.21-8.08 (m, 2H), 7.50 (dd, J = 7.9, 4.3 Hz, $1 \mathrm{H})$,

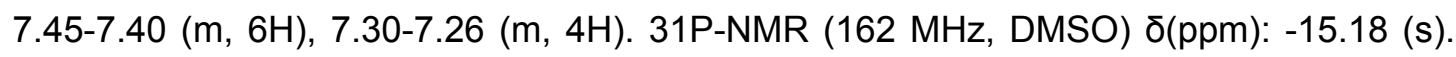
HRMS spectrometry: m/z calcd for [M + H]+ : 387.1297; found: 387.1299 . 

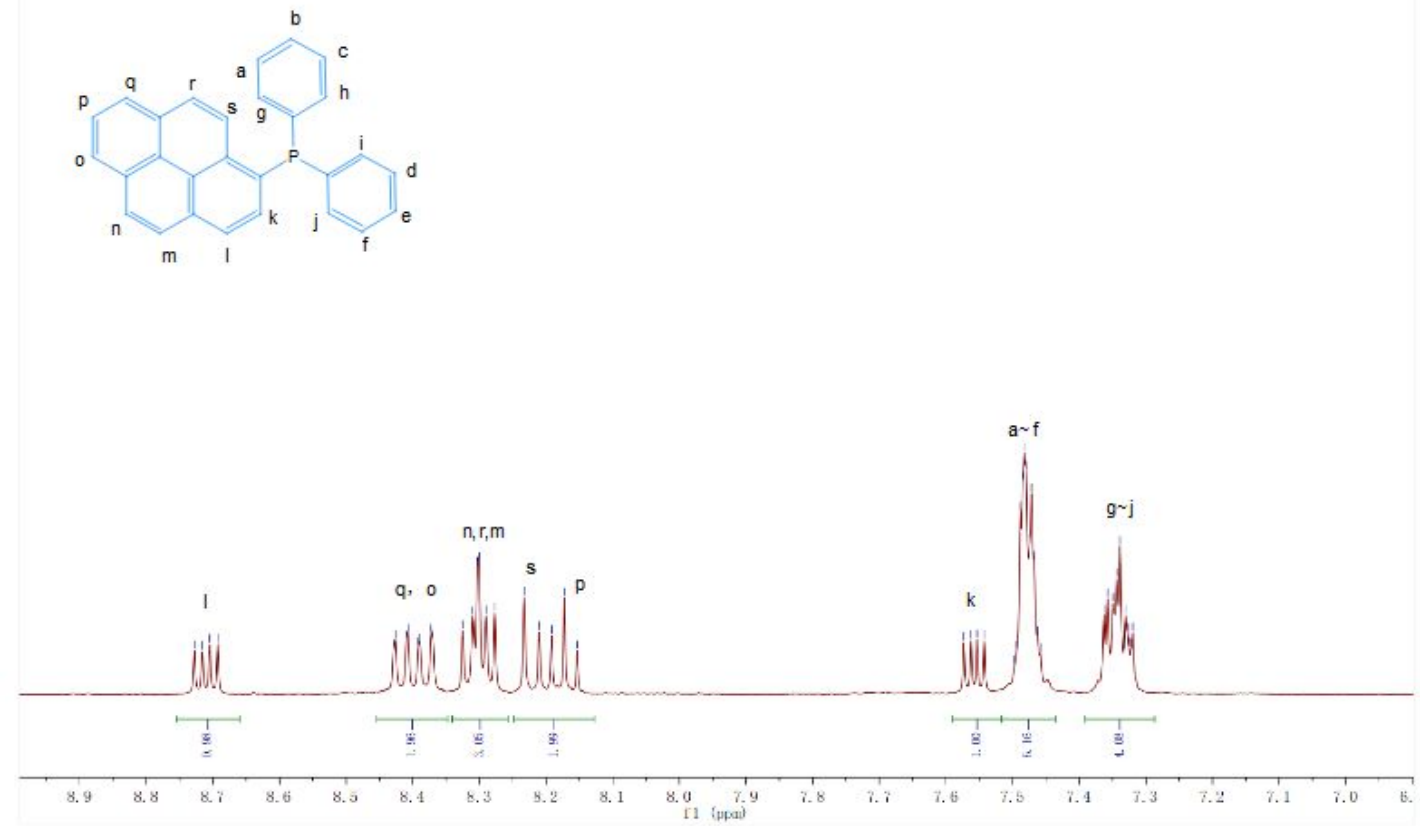

Figure S1. ${ }^{1} \mathrm{H}-\mathrm{NMR}$ spectra of DPPP.

\section{Synthesis of 1,1,2,2-Tetraphenylethane (reduced TPE: R-TPE):}

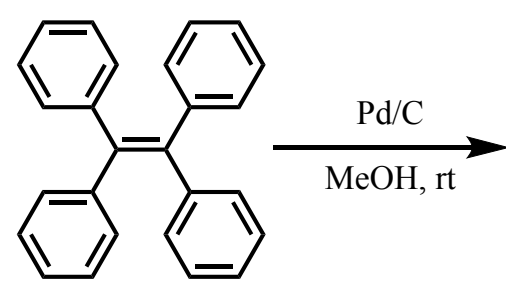

TPE

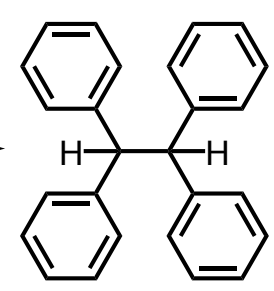

R-TPE

Scheme S2. Synthetic route of compound R-TPE.

The synthesis of R-TPE refers to literature reports. ${ }^{2}$ A suspension of $300 \mathrm{mg}$ of TPE in $50 \mathrm{~mL}$ of methanol was hydrogenated at atmospheric pressure in the presence of $180 \mathrm{mg}$ of $10 \%$ palladium/carbon. Hydrogen was allowed to adsorb for $8 \mathrm{~h}$ before reaction termination. The mixture was filtered and the solvent was then evaporated under vacuum. The crude product was purified on a silica gel column using DCM as eluent. R-TPE was isolated as a white solid in $71 \%$ yield.

${ }^{1} \mathrm{H}$ NMR (400 MHz, Chloroform-d) $\delta 7.33-7.25(\mathrm{~m}, 16 \mathrm{H}), 7.23-7.17(\mathrm{~m}, 4 \mathrm{H}), 4.89(\mathrm{t}$, $\mathrm{J}=0.9 \mathrm{~Hz}, 2 \mathrm{H})$. 


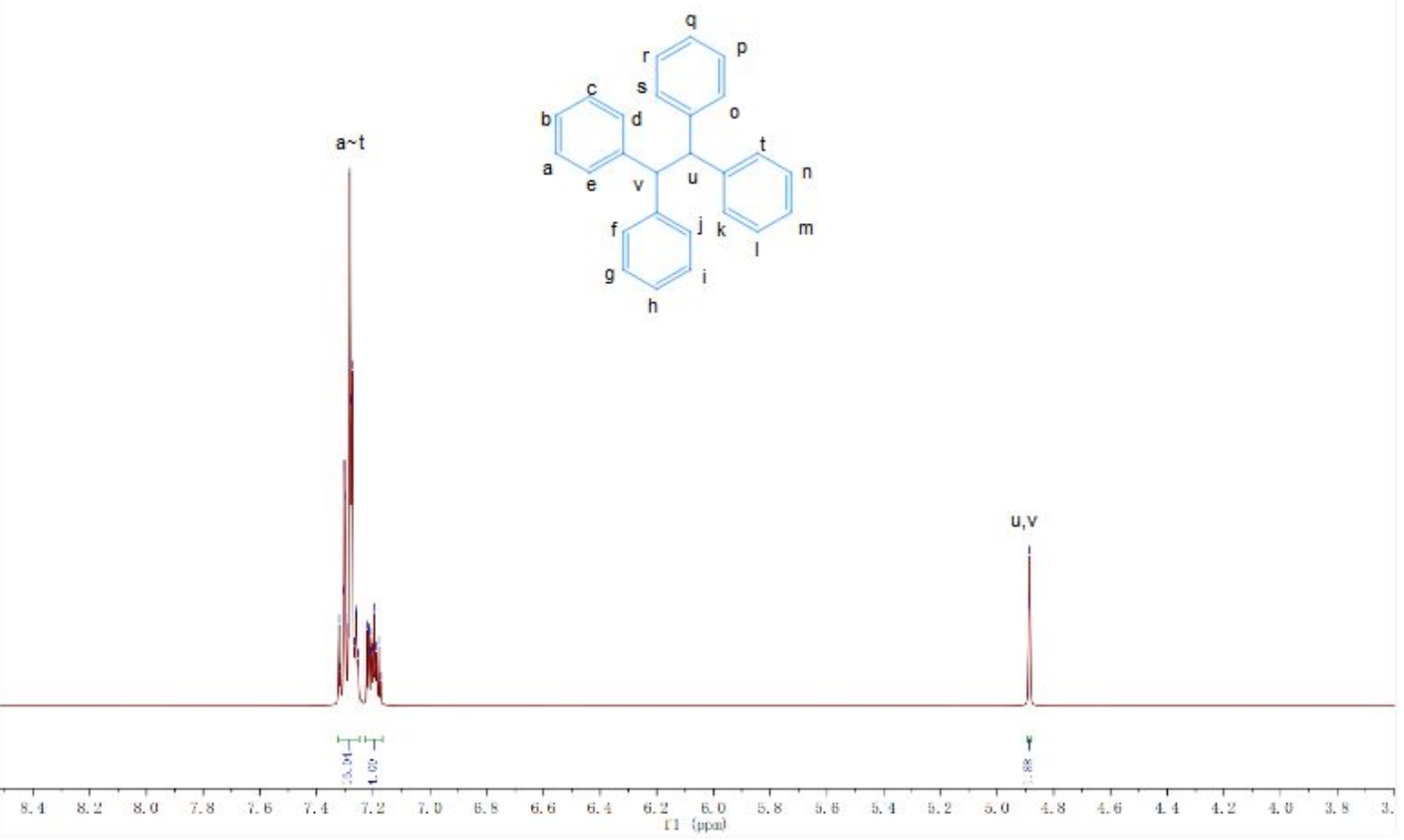

Figure S2. ${ }^{1} \mathrm{H}-\mathrm{NMR}$ spectra of R-TPE.

\section{Synthesis of Diphenyl-1-pyrenylphosphine (TPE-Ester):}

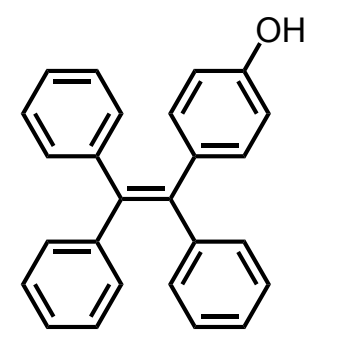

TPE-OH<smiles>[Y]C(=O)OCCCOC(=O)CBr</smiles>

1.25 equiv.

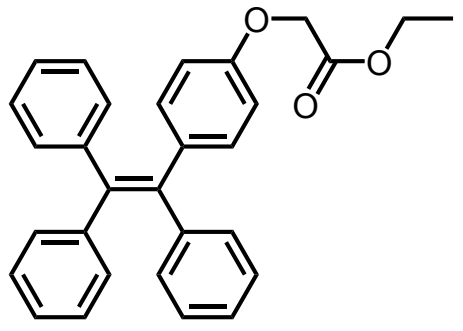

TPE-Ester

Scheme S3. Synthetic route of compound TPE-Ester.

The synthesis of TPE-Ester refers to literature reports. ${ }^{3}$ The three-neck flask charged with TPE-OH $(0.80 \mathrm{~g}, 2.29 \mathrm{mmol})$ and $\mathrm{K}_{2} \mathrm{CO}_{3}(0.67 \mathrm{~g}, 4.82 \mathrm{mmol})$ was evacuated and filled with $\mathrm{N}_{2}$. Then ethyl bromoacetate $(0.48,2.87 \mathrm{mmol})$ and $50 \mathrm{ml}$ acetonitrile were added in three neck flask and refluxed at $100{ }^{\circ} \mathrm{C}$ under an $\mathrm{N}_{2}$ atmosphere for 2 days. After the reaction, the mixture was cooled to room temperature and concentrated in vacuo, and then the crude product was purified by a silica gel column using ethyl acetate /petroleum ether (1/10, v/v) as eluent to afford a white solid intermediate (TPE-Ester). 
${ }^{1} \mathrm{H}$ NMR (300 MHz, Chloroform-d) $\delta 7.25$ (td, $\left.\mathrm{J}=4.1,3.6,2.3 \mathrm{~Hz}, 9 \mathrm{H}\right), 7.18$ (ddt, $\mathrm{J}=$ 6.1, 5.1, $2.0 \mathrm{~Hz}, 6 \mathrm{H}), 7.13-7.06(\mathrm{~m}, 2 \mathrm{H}), 6.84-6.76(\mathrm{~m}, 2 \mathrm{H}), 4.71(\mathrm{~s}, 2 \mathrm{H}), 4.42(\mathrm{q}, \mathrm{J}=$ $7.1 \mathrm{~Hz}, 2 \mathrm{H}), 1.44(\mathrm{t}, \mathrm{J}=7.1 \mathrm{~Hz}, 3 \mathrm{H})$.

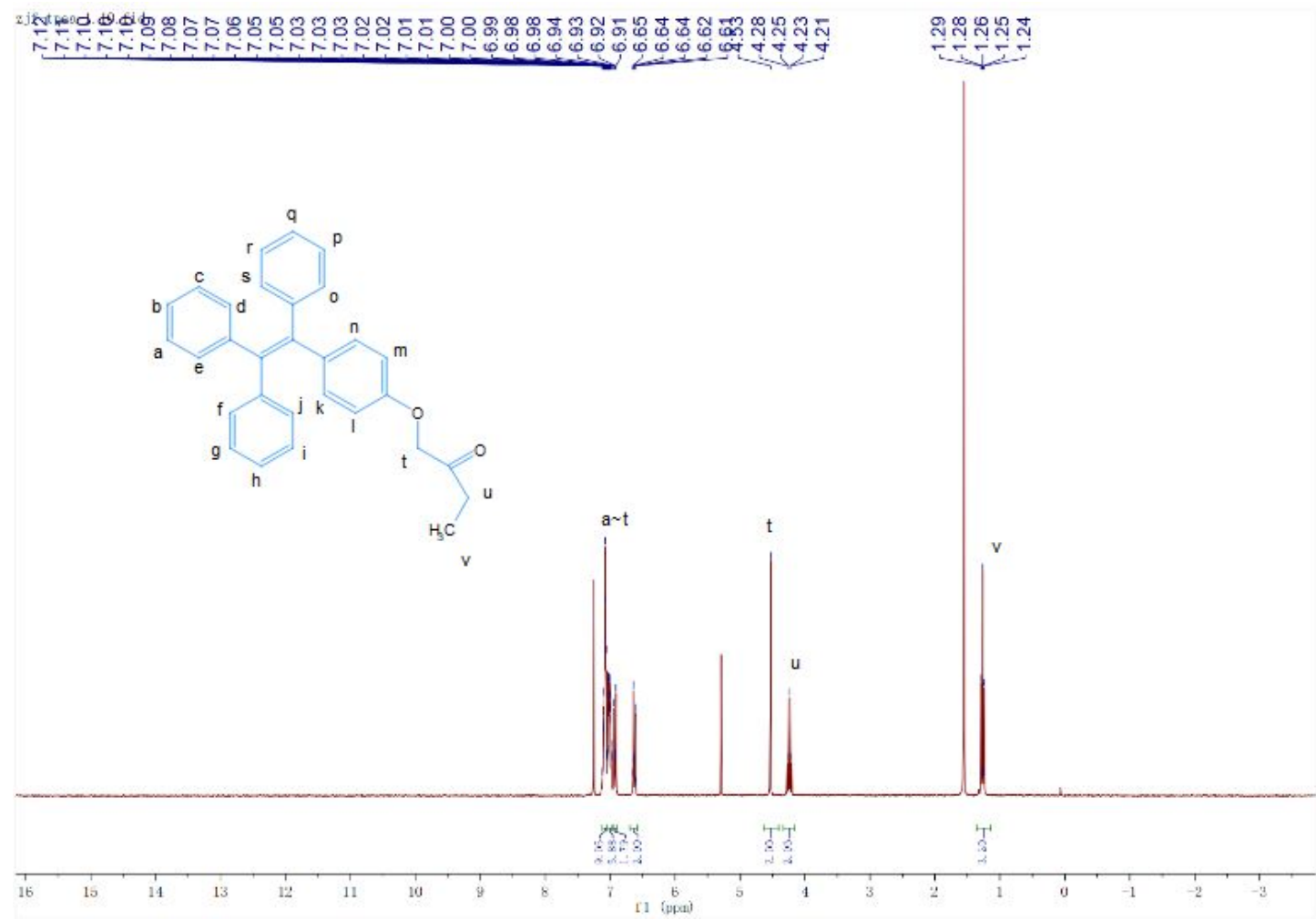

Figure S3. ${ }^{1} \mathrm{H}-\mathrm{NMR}$ spectra of TPE-Ester.

\section{Synthesis of Diphenyl-1-pyrenylphosphine (TPE-COOH):}

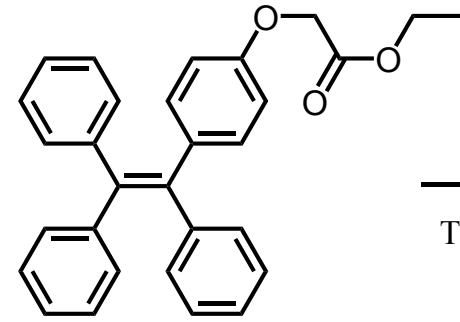

TPE-1

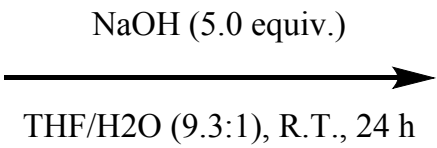

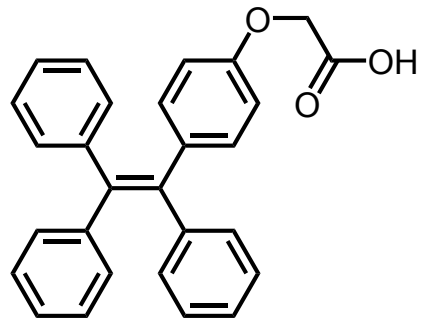

TPEA

Scheme S4. Synthetic route of compound TPE-COOH.

The synthesis of TPE-COOH refers to literature reports. ${ }^{3} 1.02 \mathrm{~g}$ of TPE-Ester was dissolved in $140 \mathrm{ml}$ of tetrahydrofuran, and $\mathrm{NaOH}(0.47 \mathrm{~g}, 11.7 \mathrm{mmol})$ was dissolved in 15 $\mathrm{ml}$ of water to prepare an alkali solution. The above tetrahydrofuran solution was added to the alkali solution, and the mixture was stirred at room temperature for 24 hours, and then the mixed solution was poured into deionized water. In water, the $\mathrm{pH}$ was adjusted to 2 
with hydrochloric acid, a white solid (TPE-COOH) was precipitated, and the solid was filtered and washed three times with water (or the organic solvent was extracted with dichloromethane) and the solvent was evaporated.

${ }^{1}$ H NMR (500 MHz, DMSO) ס 12.92 (s, 1H), 7.18 - $7.06(\mathrm{~m}, 9 \mathrm{H}), 7.01-6.91(\mathrm{~m}, 6 \mathrm{H})$, $6.91-6.81(\mathrm{~m}, 2 \mathrm{H}), 6.72-6.62(\mathrm{~m}, 2 \mathrm{H}), 4.58(\mathrm{~s}, 2 \mathrm{H})$.

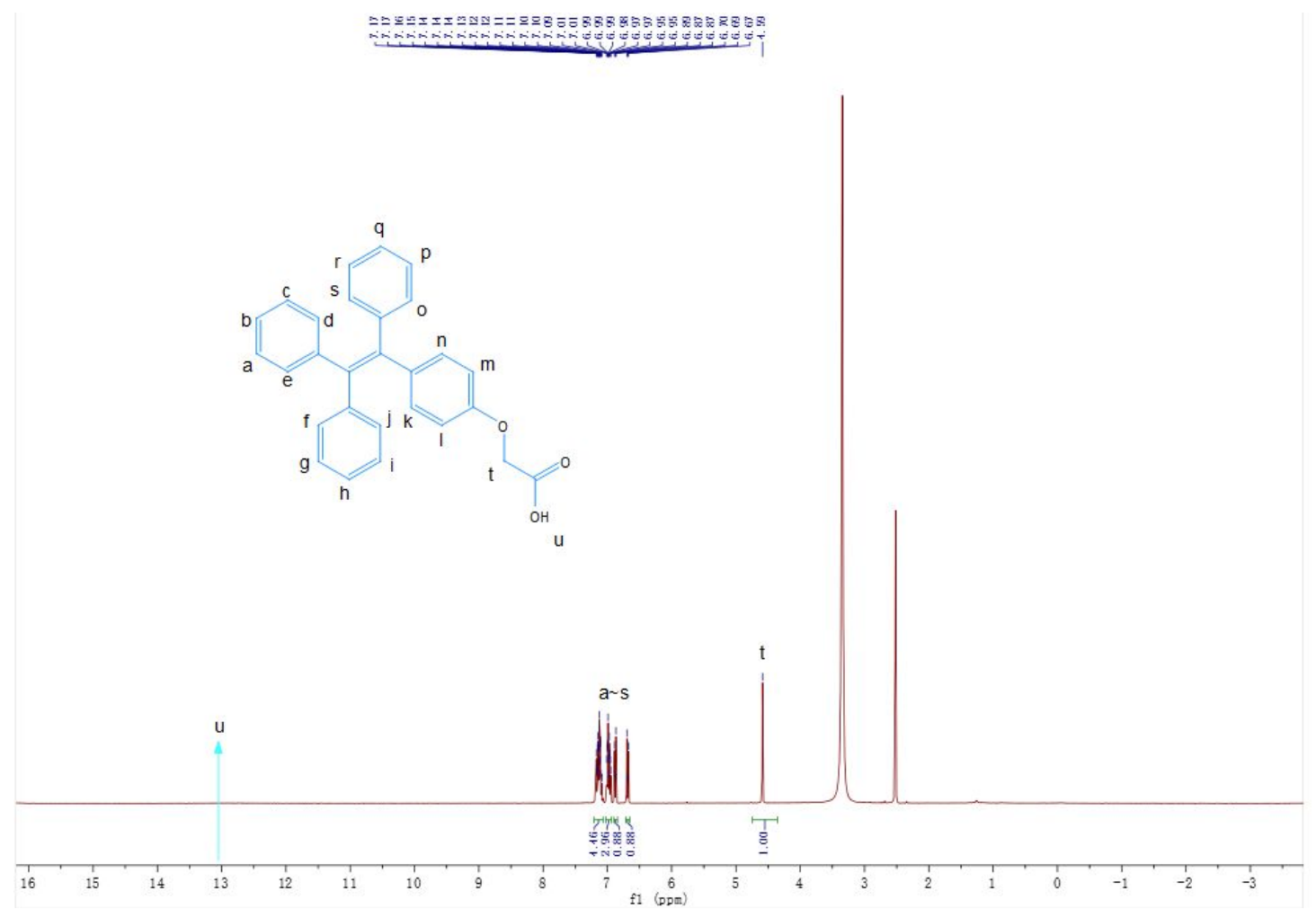

Figure S4. ${ }^{1} \mathrm{H}-\mathrm{NMR}$ spectra of TPE-COOH. Toting that the NMR signal of active hydrogen on carboxyl group is difficult to detect.

\section{Synthesis of mesoporous silica nanoparticles (MSNs): ${ }^{4}$}

A typical synthesis of MSNs with stellate morphology was performed as follows: A mixture of $192.0 \mathrm{~g}$ of cetyl-trimethylammonium tosylate (CTATos, MERK), $34.7 \mathrm{~g}$ of triethanolamine $\left(\mathrm{TEAH}_{3}\right)$ and $10 \mathrm{~L}$ of deionized water was stirred at $80^{\circ} \mathrm{C}$ for 1 hour, and then $1458.0 \mathrm{~g}$ of tetraethyl-orthosilicate (TEOS) was quickly added into the surfactant solution. It is important to note that, TEOS was quickly added only after the surfactant was completely dissolved in water containing the small organic amine (SOA). The final mixture had the molar composition: $1.0 \mathrm{SiO}_{2}: 0.06 \mathrm{CTATos}: 0.026 \mathrm{SOA}: 80.0 \mathrm{H}_{2} \mathrm{O}$. The mixture was stirred at $80^{\circ} \mathrm{C}$ with a stirring speed of $1200 \mathrm{rpm}$ for another 2 hours. The synthesized 
MSNs were filtered (final $\mathrm{pH}=7.3$ for 2 and 7.5 for 3 ), washed, and dried in the oven at $100{ }^{\circ} \mathrm{C}$ for 20 hours. The final yield of the collected product was around $560 \mathrm{~g}(93 \%$ in silica and $85 \%$ in surfactant). The final products were collected by filtration, washed, and dried.

\section{Post-Grafting of targeted -COOH and- $\mathrm{NH} 2$ organic functions on MSNs: ${ }^{5}$}

To remove the templates, the MSNs were washed using a slight excess of $\mathrm{HCl}(1.1$ eq.) in ethanol solution followed by drying at $353 \mathrm{~K}$ overnight. Before grafting, $1.0 \mathrm{~g}$ of MSNs was further dried at $403 \mathrm{~K}$ for $5 \mathrm{~h}$ and cooled down to RT under argon atmosphere. Then, dry toluene $(40 \mathrm{ml})$ and silylating agent (TESPSA or APTMS: $9 \mathrm{ml}, 4.2 \times 10^{-2} \mathrm{~mol}$ ) were added and stirred for $1 \mathrm{~h}$ at RT and then refluxed for $16 \mathrm{~h}$ at $383 \mathrm{~K}$. The solid obtained by filtration and finally washed 3 times with toluene, acetone and ethanol, and dried in air at $353 \mathrm{~K}$ overnight. The carboxylate grafted MSNs was finally obtained by further acidizing from anhydride functionalized MSNs.

\section{Processed method of DMSO test sample}

DMSO fluorescence test samples need to control the temperature near the melting point of $18.45^{\circ} \mathrm{C}$, so that the DMSO is in a state of solid-liquid mixing (we use the method of melting at room temperature after refrigeration), and then add sodium hydroxide solution (1M) or sodium hydroxide solid, which is mixed uniformly by ultrasonic. It is not necessary to maintain the temperature of melting point during the test.

\section{Characterization}

${ }^{1}$ HNMR spectra were obtained using Bruker DPX-400 or Bruker DPX-300 spectrometer. Chemical shifts were reported in ppm from $\mathrm{CDCl}_{3}$ and $\mathrm{DMSO}^{-\mathrm{d}_{6}}$ with the solvent resonance as the internal standard. The following abbreviations were used to designate chemical shift multiplicities: $\mathrm{s}=$ singlet, $\mathrm{d}=$ doublet, $\mathrm{t}=$ triplet, $\mathrm{q}=$ quartet, $\mathrm{h}=$ heptet, $\mathrm{m}=$ multiplet, $\mathrm{br}=$ broad. Absorption (or extinction) spectra were collected with a two-beam UV-Vis spectrometer (PERSEE TU-1901, China). Fluorescence was measured by using a FluorMax-4 fluorimeter (Horiba, Japan). DLS was measured by Zetasizer Nano ZS90 (Malvern Instruments Limited). Fluorescence lifetime was measured with a 
homebuilt time-correlated single photon counting (TCSPC) system with a time resolution of sub-100 ps. The quantum yield (QY) was determined by absolute methods 1 with FluorMax-4 by using integrating sphere (Quanta- $\varphi$, Horiba) with $150 \mathrm{~mm}$ size and open hole (less than 1.9\%) using Polytetrafluoroethylene (PTFE, 90\% reflectivity) as an internal reflection material. Rhodamine $B$ was used as standard sample to calibrate the measurement system. The transient absorption (TA) measurements were conducted in a femtosecond transient absorption spectrometer (Helios Fire, Ultrafast System) with pump probe beams generated with a Ti:sapphire laser system (Astrella, $800 \mathrm{~nm}, 100 \mathrm{fs}, 7$ $\mathrm{mJ} /$ pulse, and $1 \mathrm{kHz}$ repetition rate, Coherent Inc.). A fraction of the fundamental beam was focused into the sapphire to generate a white light continuum probe beam from 420 to $800 \mathrm{~nm}$. Another fraction of the fundamental beam was used to produce pump beams via an optical parametric amplifier (OPerA Solo, Coherent Inc.), and the power was adjusted to $\sim 0.3 \mathrm{~mW}$ by a neutral-density filter wheel. All experiments were carried out at room temperature. $2 \mathrm{~mm}$ cuvettes were used for all spectroscopy measurements. 


\section{Experimental results}
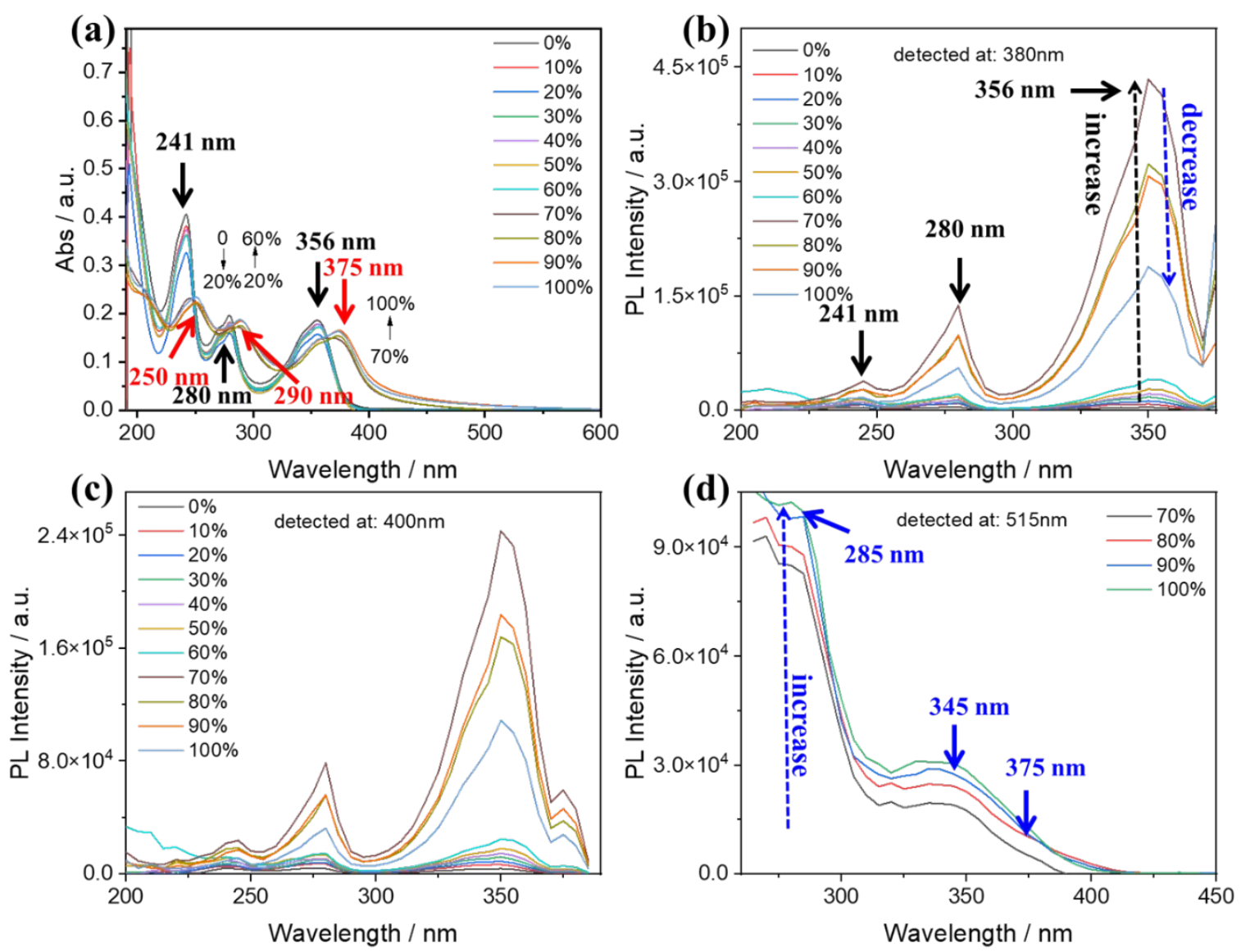

Figure S5. Absorption (a), excitation spectra of DPPP molecules at varied emission bands of $380 \mathrm{~nm}(\mathrm{~b}), 400 \mathrm{~nm}$ (c) and $515 \mathrm{~nm}(\mathrm{~d})$. 

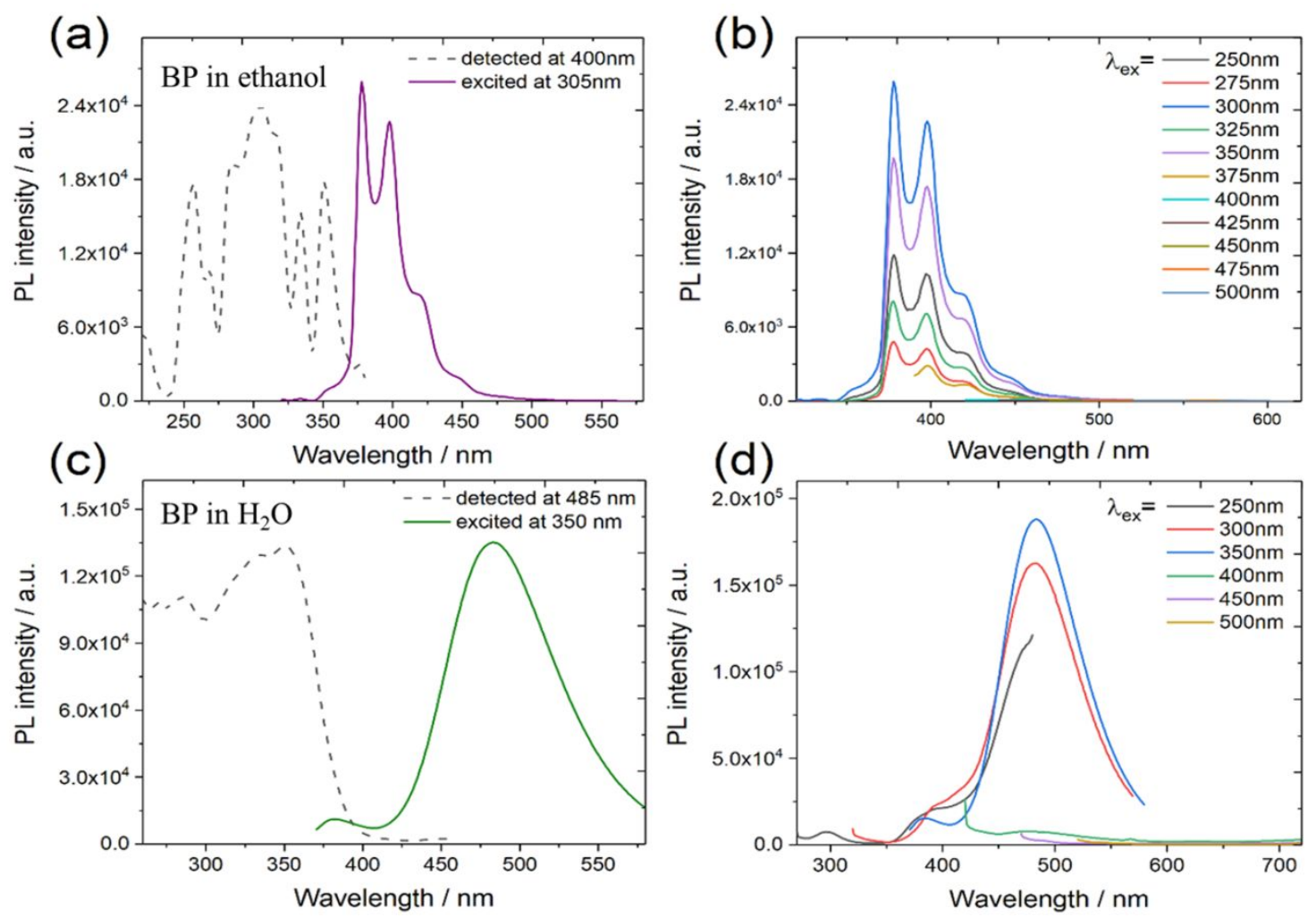

Figure S6. Excitation (dotted line) and emission spectra (solid line) of BP in ethanol (a) and water solution (c). (b) and (d) Corresponding emission spectra excited at different wavelength. 


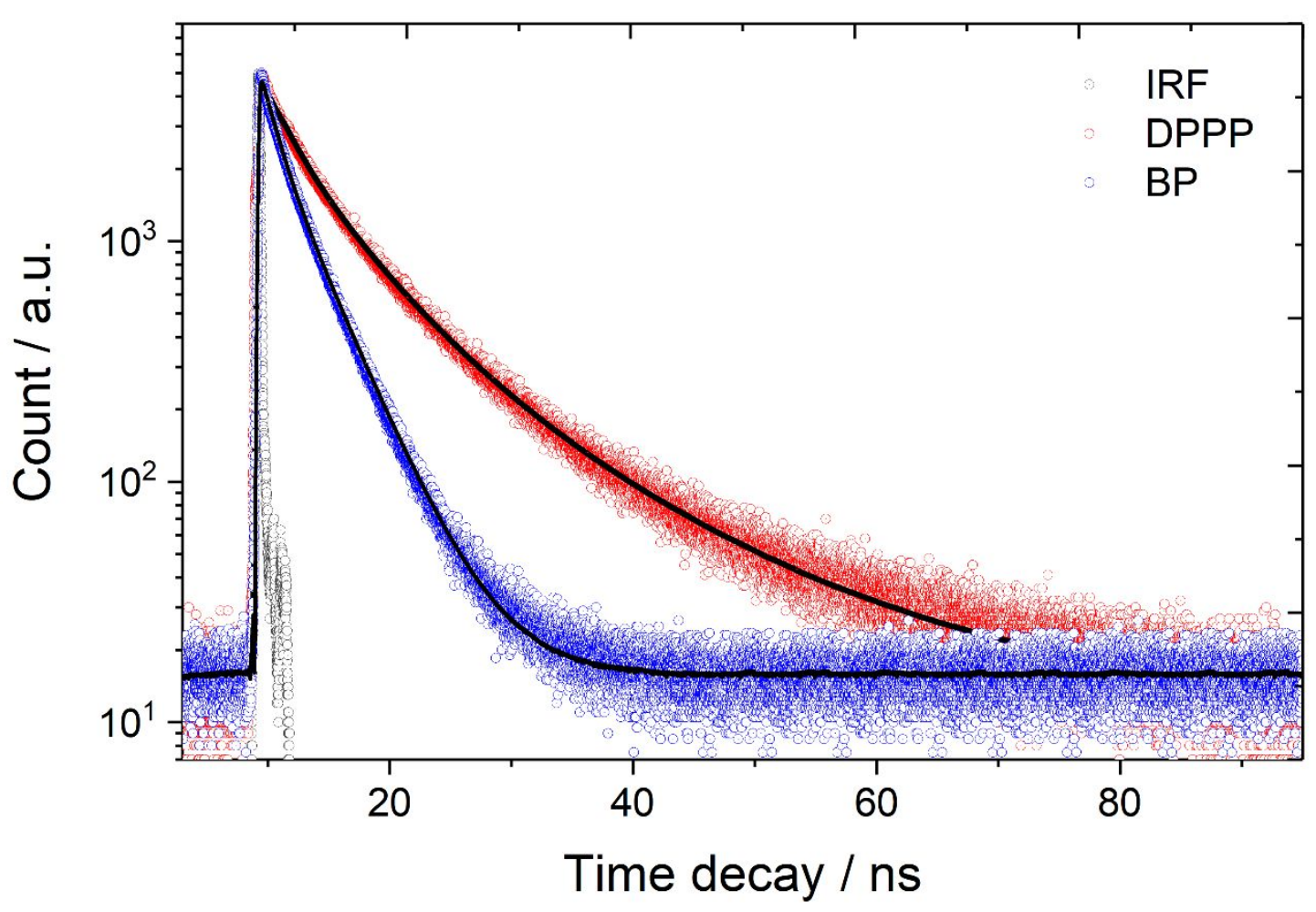

Figure S7. Time-resolved luminescence decay profiles of DPPP (red) and BP (blue) in water solution. Fitting curves were obtained by reconvoluting the instrument response function (IRF) with tri-exponential model $\sum \alpha_{i}\left(-t / \tau_{i}\right) \quad(\mathrm{i}=1 \ldots 3)$.

Table S1. Lifetime parameters of DPPP (red) and BP (blue) in water solution. The steady state optical characterizations are presented in Figure 1, $c$ and d. (the physical meaning in our case of an average lifetime is weighted average $\mathrm{PL}$ decay time by a three-component nonlinear fitting.)

\begin{tabular}{|c|c|c|c|c|c|c|c|c|}
\hline Item & $\begin{array}{c}\boldsymbol{\alpha}_{\mathbf{1}} \\
\mathbf{( \% )}\end{array}$ & $\begin{array}{c}\boldsymbol{\alpha}_{\mathbf{2}} \\
\mathbf{( \% )}\end{array}$ & $\begin{array}{c}\boldsymbol{\alpha}_{3} \\
(\mathbf{\%})\end{array}$ & $\begin{array}{c}\boldsymbol{\tau}_{1} \\
(\mathbf{n s})\end{array}$ & $\begin{array}{c}\boldsymbol{\tau}_{2} \\
(\mathbf{n s})\end{array}$ & $\begin{array}{c}\boldsymbol{\tau}_{3} \\
(\mathbf{n s})\end{array}$ & $\begin{array}{c}\text { Average } \\
\text { lifetime }\end{array}$ & QY (\%) \\
\hline DPPP & 38.5 & 49.9 & 11.6 & 2.0 & 5.7 & 14.4 & $7.9 \mathrm{~ns}$ & 8.4 \\
\hline BP & 59.7 & 40.3 & -- & 1.1 & 3.4 & -- & $2.6 \mathrm{~ns}$ & 2.1 \\
\hline
\end{tabular}



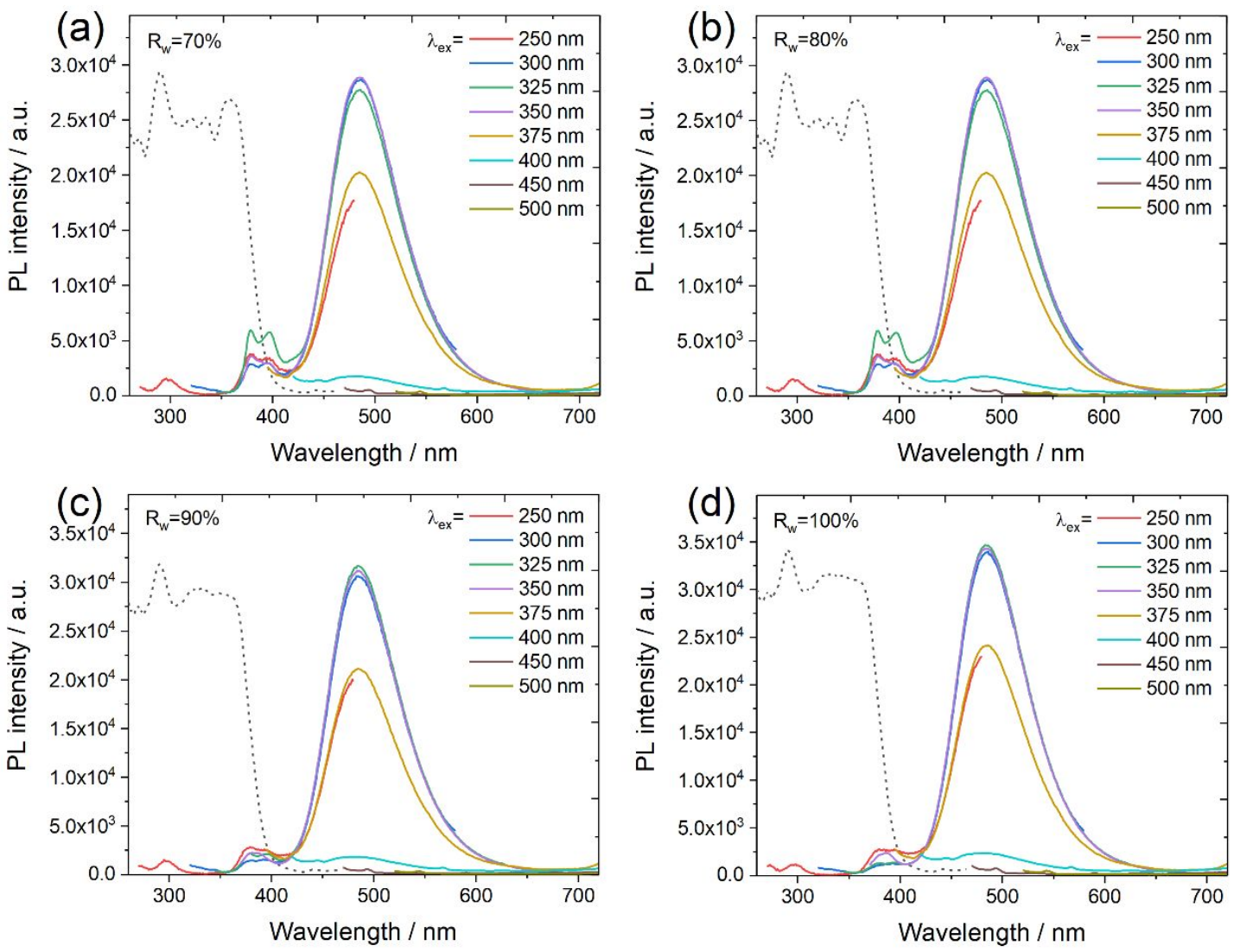

Figure S8. Excitation (dotted line) and emission spectra (solid line) of BP mixture solvent with different water fraction. The emission wavelengths are excitation and $R_{W}$ -independent.

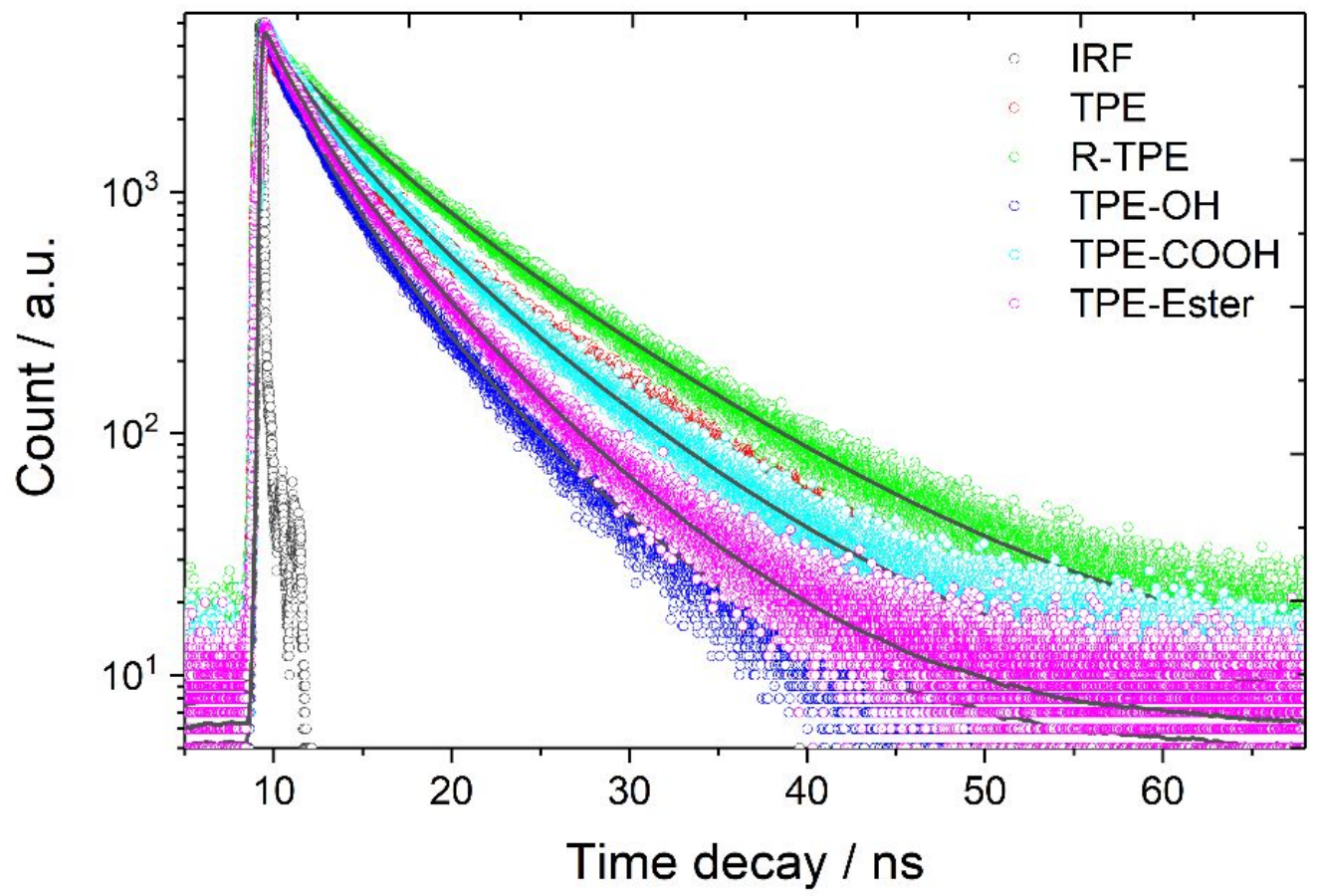

Figure S9. Time-resolved luminescence decay profiles of five kinds of TPE derivatives in water solution. Fitting curves were obtained by reconvoluting the instrument response function (IRF) with tri-exponential model $\sum \alpha_{i}\left(-t / \tau_{i}\right) \quad(\mathrm{i}=1 \ldots 3)$. 
Table S2. Lifetime parameters of five kinds of TPE derivatives in water solution. The steady state optical characterizations are presented in Figure 2, a-e. (the physical meaning in our case of an average lifetime is weighted average PL decay time by a three-component nonlinear fitting.)

\begin{tabular}{|c|c|c|c|c|c|c|c|c|}
\hline Item & $\boldsymbol{\alpha}_{\mathbf{1}}(\%)$ & $\boldsymbol{\alpha}_{\mathbf{2}}(\%)$ & $\boldsymbol{\alpha}_{\mathbf{3}}(\%)$ & $\boldsymbol{\tau}_{\mathbf{1}}(\mathbf{n s})$ & $\boldsymbol{\tau}_{\mathbf{2}}(\mathbf{n s})$ & $\boldsymbol{\tau}_{\mathbf{3}}(\mathbf{n s})$ & Average lifetime & QY (\%) \\
\hline TPE & 38.0 & 40.9 & 21.1 & 1.7 & 4.8 & 9.6 & $6.5 \mathrm{~ns}$ & 4.5 \\
\hline R-TPE & 42.3 & 31.3 & 26.4 & 3.3 & 6.5 & 10.2 & $7.4 \mathrm{~ns}$ & 9.4 \\
\hline TPE-OH & 38.2 & 48.1 & 13.7 & 0.9 & 3.0 & 6.7 & $4.0 \mathrm{~ns}$ & 3.5 \\
\hline TPE-COOH & 30.6 & 47.8 & 21.6 & 1.3 & 4.0 & 8.4 & $5.7 \mathrm{~ns}$ & 5.1 \\
\hline TPE-Ester & 41.3 & 45.2 & 13.5 & 1.3 & 3.9 & 7.5 & $4.6 \mathrm{~ns}$ & 4.7 \\
\hline & & & & & & & & \\
\hline
\end{tabular}



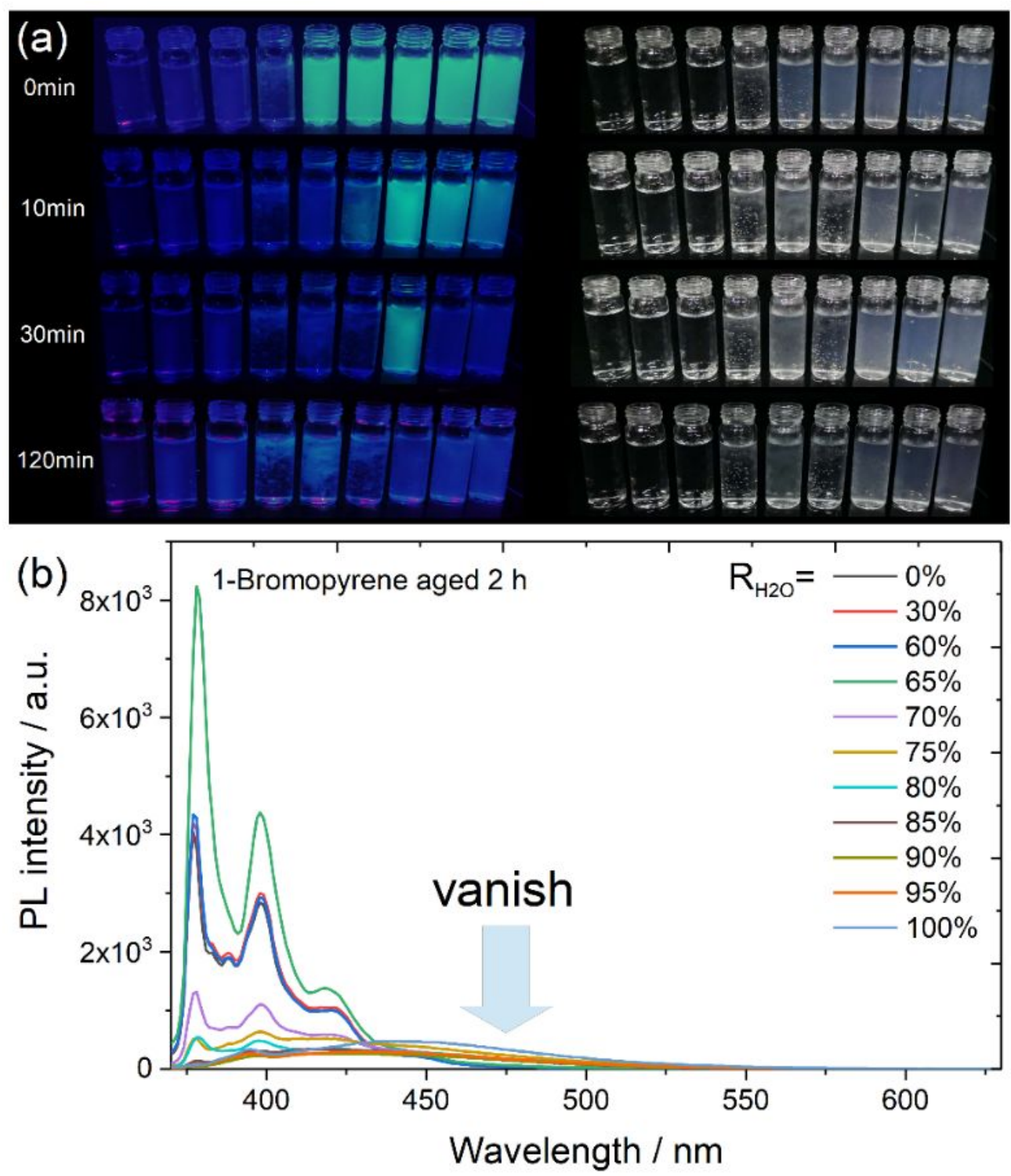

Figure S10. (a) Photograph of 1-Bromopyrene in mixed solvents with different volume fraction $R_{\mathrm{H} 2 \mathrm{O}}$ at different times under UV light (left) and room light (right). (b) Corresponding emission spectrum after aged 2 hours. 


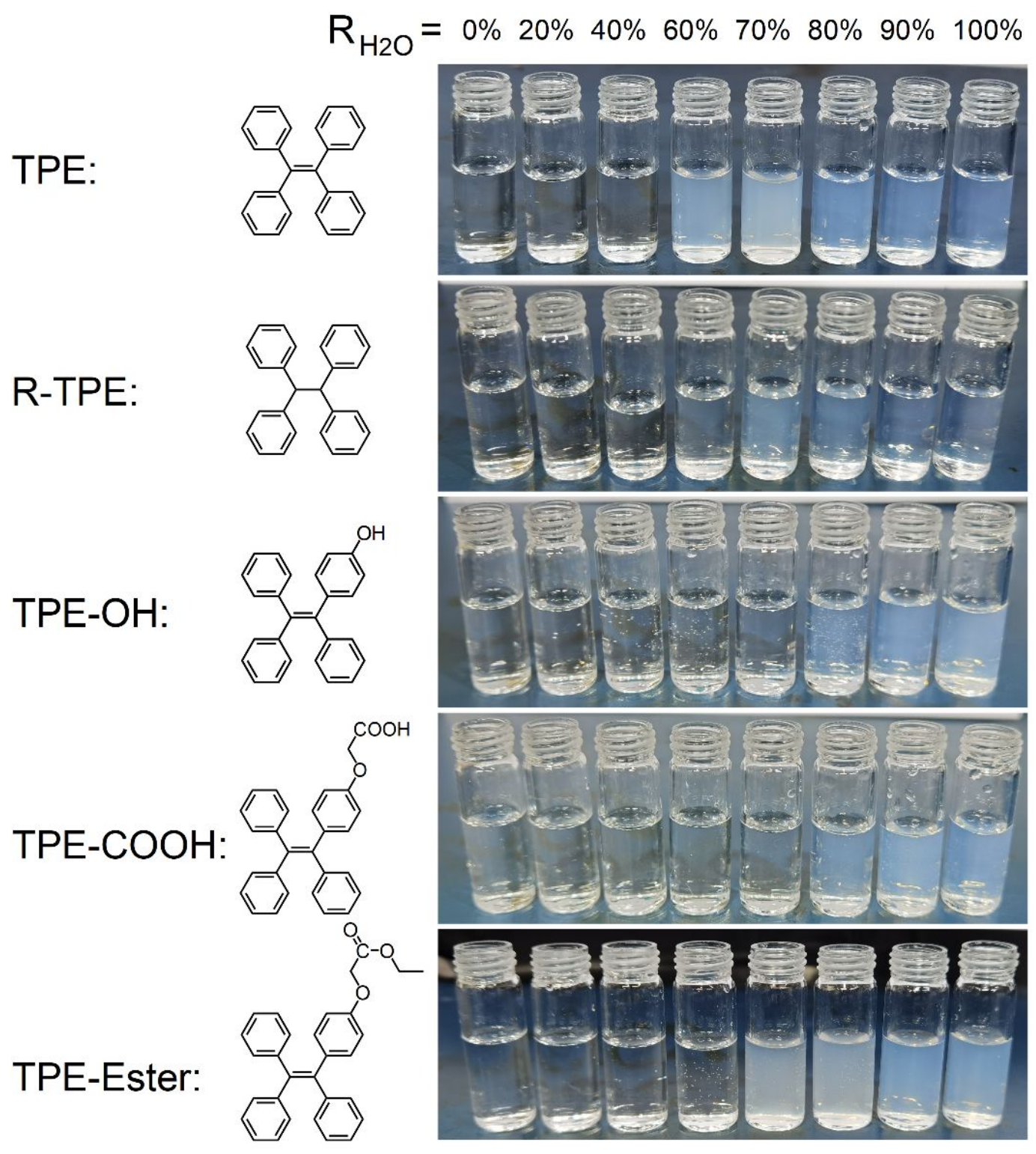

Figure S11. Photographs of Five kinds of TPE derivants in mixed solvents with different volume fraction $\mathrm{R}_{\mathrm{H} 2 \mathrm{O}}$ under room light. 

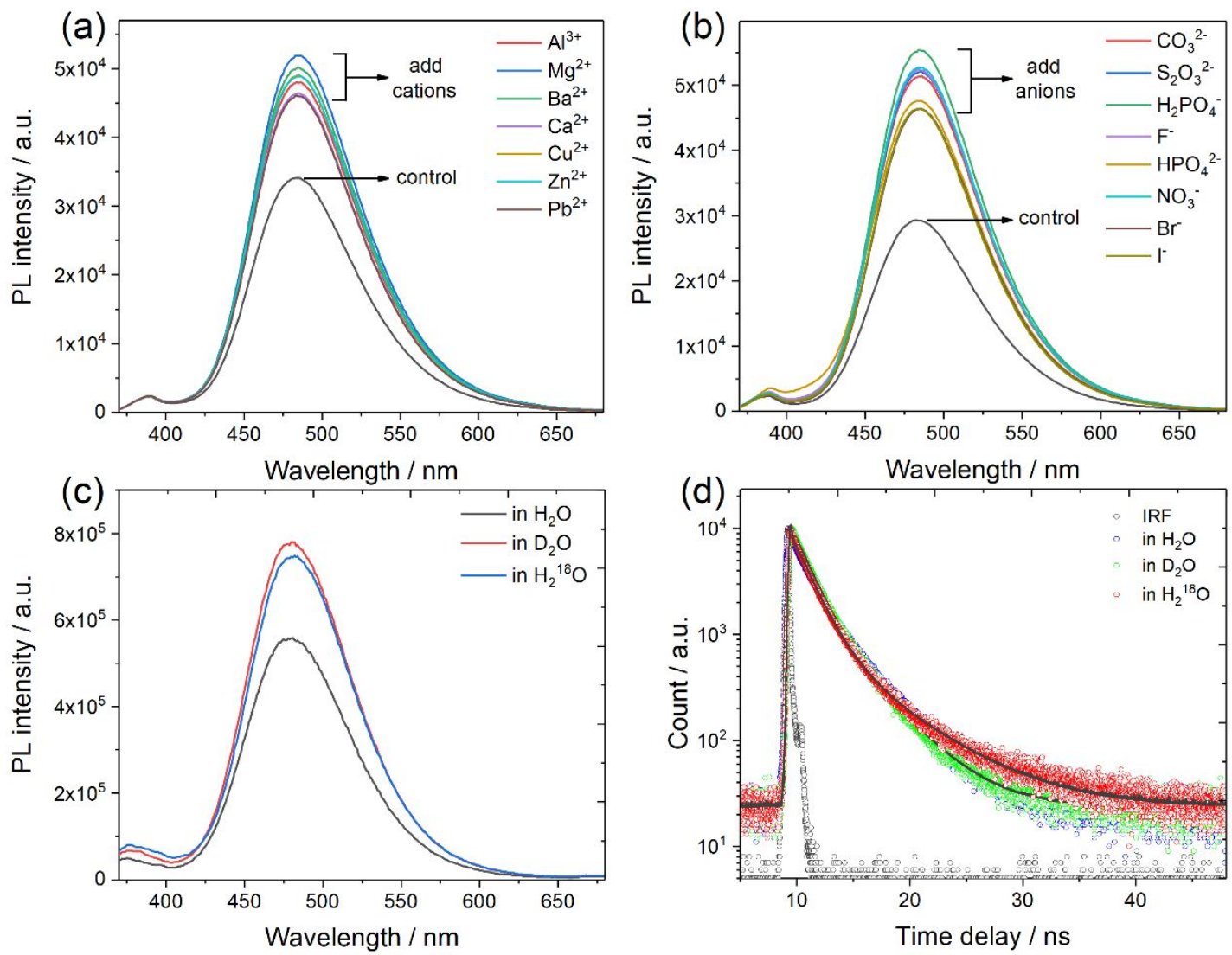

Figure S12. Emission spectra of BP in water solution with varied inorganic salts. Cation effect of nitrate salts (a) and Anions effect of ammonium salts (b). (c) Emission spectra of BP in $\mathrm{H}_{2} \mathrm{O}, \mathrm{D}_{2} \mathrm{O}$ and $\mathrm{H}_{2}{ }^{18} \mathrm{O}$. (d) Corresponding time-resolved luminescence decay profiles. Fitting curves were obtained by reconvoluting the instrument response function (IRF) with bi-exponential model $\sum \alpha_{i}\left(-t / \tau_{i}\right) \quad(\mathrm{i}=1 \ldots 2)$. The concentration of $\mathrm{BP}$ and ions was 0.1 and $25 \mathrm{mmol} / \mathrm{L}$. All spectra are obtained with $350 \mathrm{~nm}$ excitation.

Table S3. Lifetime parameters of BP in different water solution. The steady state optical characterizations are presented in Figure S10c.

\begin{tabular}{|c|c|c|c|c|c|}
\hline Item & $\boldsymbol{\alpha}_{\mathbf{1}}(\%)$ & $\boldsymbol{\alpha}_{\mathbf{2}}(\%)$ & $\boldsymbol{\tau}_{\mathbf{1}}(\mathbf{n s})$ & $\boldsymbol{\tau}_{\mathbf{2}}(\mathbf{n s})$ & Average lifetime \\
\hline In $\mathrm{H}_{\mathbf{2}} \mathbf{O}$ & 59.7 & 40.3 & 1.1 & 3.4 & $2.6 \mathrm{~ns}$ \\
\hline In $\mathrm{D}_{\mathbf{2}} \mathbf{O}$ & 77.5 & 22.5 & 1.4 & 3.6 & $2.3 \mathrm{~ns}$ \\
\hline${\operatorname{In~} \mathrm{H}_{\mathbf{2}}{ }^{18} \mathbf{O}}^{2}$ & 89.0 & 11.0 & 1.6 & 5.5 & $2.7 \mathrm{~ns}$ \\
\hline
\end{tabular}




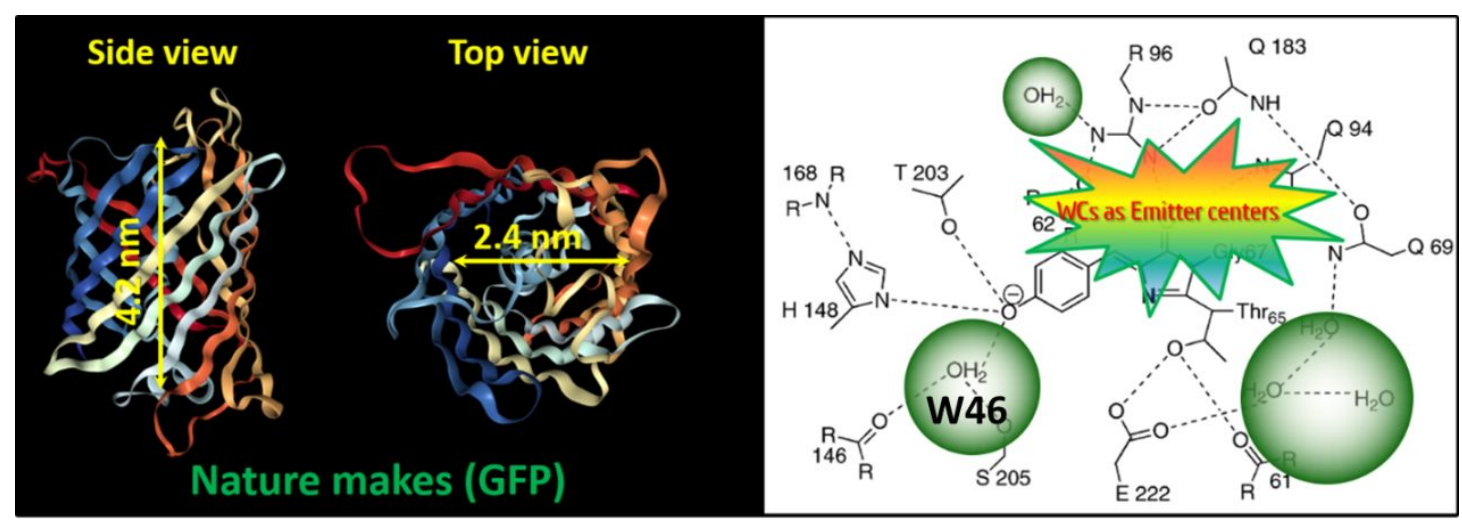

Figure S13. Structure of green fluorescent protein (GFP) with $\sim 3 \mathrm{~nm}$ confined nanocavity and the important role of water in fluorescence process. ${ }^{6}$

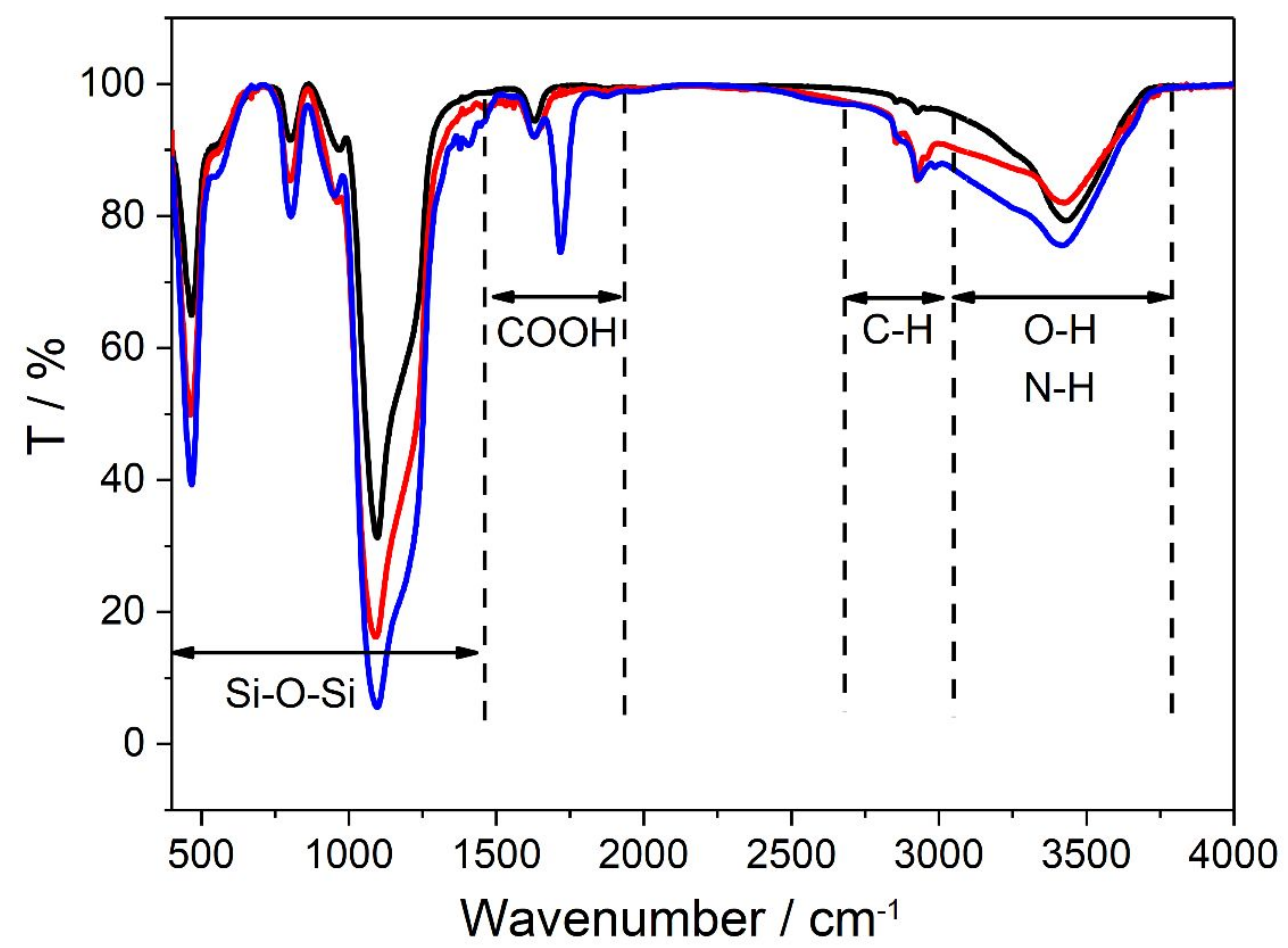

Figure S14. FT-IR spectra of DMSNs (black), DMSNs-NH2 (red) and DMSNs-COOH (blue). The vibration peak centered at $\sim 1717 \mathrm{~cm}^{-1}, 3000 \sim 3600 \mathrm{~cm}^{-1}$, was attributed to the stretching vibration of $\mathrm{C}=\mathrm{O}, \mathrm{N}-\mathrm{H} / \mathrm{O}-\mathrm{H}$. The vibration peak centered at $\sim 2850 \mathrm{~cm}^{-1}$ and $2925 \mathrm{~cm}^{-1}$ corresponding to the symmetric and asymmetric vibrations of methylene. The FT-IR spectrum clearly evidenced the grafting of amino and carboxyl groups on the nanopores. 

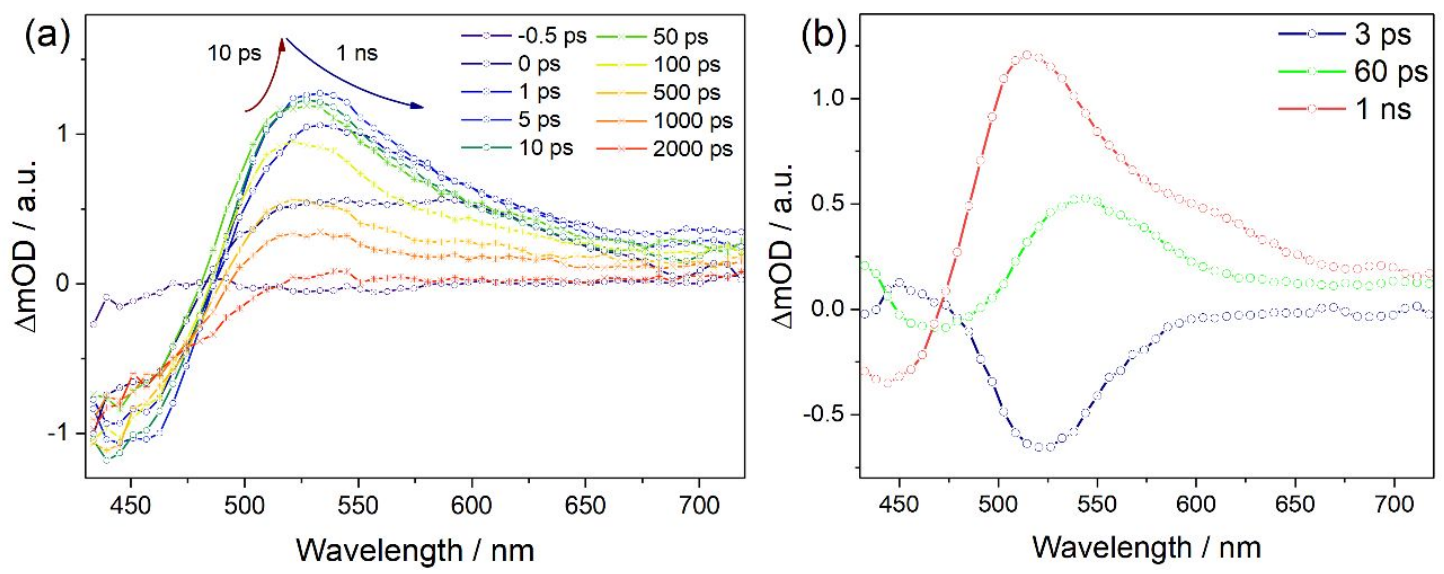

Figure S15. (a) Two-dimensional transient absorption (TA) spectra at selected time delays for BP in water solution. (b) Species-associated spectra obtained from global fitting on the TA data.

Table S4. Time constants of BP water solutions obtained using three components fitting. The fitting parameters was little different with global fitting results, since the global fitting need to take all wavelength-decay into consideration.

\begin{tabular}{|c|c|c|c|c|c|c|c|}
\hline \multicolumn{2}{|c|}{ Item } & $\boldsymbol{\alpha}_{1}(\%)$ & $\boldsymbol{\alpha}_{\mathbf{2}}(\%)$ & $\boldsymbol{\alpha}_{3}(\%)$ & $\tau_{1}(\mathbf{p s})$ & $\tau_{2}(\mathbf{p s})$ & $\tau_{3}(\mathbf{p s})$ \\
\hline \multirow{3}{*}{ In water } & $455 \mathrm{~nm}$ & 44.3 & 26.3 & 29.4 & 3 & 15 & 2500 \\
\cline { 2 - 8 } & $530 \mathrm{~nm}$ & 22.2 & 31.3 & 46.5 & 3 & 150 & 1500 \\
\hline
\end{tabular}

\section{Reference}

1. Brissos, R. F.; Clavero, P.; Gallen, A.; Grabulosa, A.; Barrios, L. A.; Caballero, A. B.;

Korrodi-Gregorio, L.; Perez-Tomas, R.; Muller, G.; Soto-Cerrato, V.; Gamez, P., Highly

Cytotoxic Ruthenium(II)-Arene Complexes from Bulky 1-Pyrenylphosphane Ligands. Inorg.

Chem. 2018, $57(23), 14786-14797$.

2. Xie, N., Hong Kong University of Science and Technology, Hong Kong, China. PhD thesis 2013.

3. Zhang, W.; Chang, H.; Ai, J.; Che, S.; Duan, Y.; Han, L., Spontaneous chiral self-assembly of achiral AIEgens into AIEgen-silica hybrid nanotubes. Chem. Commun. 2019, 
55(96), 14438-14441.

4. Zhang, K.; Xu, L. L.; Jiang, J. G.; Calin, N.; Lam, K. F.; Zhang, S. J.; Wu, H. H.; Wu, G. D.; Albela, B.; Bonneviot, L.; Wu, P., Facile large-scale synthesis of monodisperse mesoporous silica nanospheres with tunable pore structure. J. Am. Chem. Soc. 2013, 135 (7), $2427-2430$

5. Zhang, K.; Lam, K. F.; Albela, B.; Xue, T.; Khrouz, L.; Hou, Q. W.; Yuan, E. H.; He, M. Y.; Bonneviot, L., Mononuclear-Dinuclear Equilibrium of Grafted Copper Complexes Confined in the Nanochannels of MCM-41 Silica. Chem-Eur J 2011, 17 (50), 14258-14266.

6. Ormo, M.; Cubitt, A. B.; Kallio, K.; Gross, L. A.; Tsien, R. Y.; Remingtont, S. J., Crystal Structure of the Aequorea victoria Green Fluorescent Protei. Science 1996, 273, 1392-1395. 